\title{
Revinter
}

\section{Coffea arabica L.: potencialidades e ações medicinais}

Cleidisson Nunes de Carvalhoi

Ykaro Richard Oliveira ${ }^{\text {ii }}$

Paulo Henrique da Silva ${ }^{\text {iii }}$

Maria Carolina de Abreu ${ }^{\text {iv }}$

\section{Registro DOI: http://dx.doi.org/10.22280/revintervol11ed3.380}

\section{Resumo}

Este trabalho tem como objetivo responder aos questionamentos: quais as indicações do uso da espécie Coffea arabica, quais as principais formas desse uso e quais são as partes da planta aplicadas com finalidade medicinal? Para esta revisão foram utilizados apenas recursos primários como os bancos de dados SciELO, ScienceDirect e Web CAPES. Foram selecionados documentos e artigos compreendendo os aspectos envolvidos direto ou indiretamente nas propriedades de C. arabica, a exposição humana e animal e consequências da intoxicação, incluindo artigos originais e de revisão. Como resultados, nos artigos explorados os principais assuntos abordados referentes ao café foram: atividade antioxidante: alta atividade de inibição da peroxidação lipídica; efeitos fisiológicos: respostas psicoativas (estado de alerta e mudanças de humor) e neurológicas (hiperatividade infantil e doença de Parkinson); efeito antiinflamatório; bioatividade dos ácidos clorogênicos, que possuem propriedades antioxidantes e bacterianas. Assim, C. arabica apresenta em sua composição química: alcaloides, ácidos orgânicos, flavonoides, diterpenos, salicilatos, EDTA, ácido benzoico, derivados nicotínicos, óleos essenciais, vitaminas, minerais e ações medicinais relacionadas ao Alzheimer, hiperatividade, doenças crônicas, efeito anti-inflamatório, doenças cardiovasculares e outros benefícios à saúde humana.

Palavras-chave: Ácidos clorogênicos. Atividade antioxidante. Café. Cafeína. Uso medicinal.

\section{Coffea arabica L.: Potentialities and medicinal actions}

\begin{abstract}
This paper aims to answer the questions: which are the indications of the use of Coffea arabica, which are the main forms of this use and which are the parts of the plant applied for medicinal purposes? For this review, only primary resources, as the SciELO, ScienceDirect and Web CAPES databases were used. We selected documents covering aspects directly or indirectly involved in the properties of $\mathrm{C}$. arabica, human and animal exposure and consequences of intoxication, including original and review articles. As results, in the articles explored the main subjects addressed concerning coffee were: antioxidant activity: high inhibition activity of lipid peroxidation; physiological effects: psychoactive responses (alertness and mood changes) and neurological (childhood hyperactivity and Parkinson's disease); anti-inflammatory effect; bioactivity of chlorogenic acids, which have antioxidant and bacterial properties. Thus, C. Revinter, v. 11, n. 03, p. 87-105, out. 2018.




\section{Revinter}

arabica presents in its chemical composition: alkaloids, organic acids, flavonoids, diterpenes, salicylates, EDTA, benzoic acid, nicotinic derivatives, essential oils, vitamins, minerals and medicinal actions related to Alzheimer's, hyperactivity, chronic diseases, anti-inflammatory, cardiovascular diseases and others benefits to human health.

Keywords: Antioxidant activity. Caffeine. Chlorogenic acids. Coffe. Medicinal Use.

\section{Recebido em 13/04/2018 Aceito em 02/10/2018}

\section{INTRODUÇÃO}

A espécie Coffea arabica L. conhecida popularmente como café, pertence à família Rubiaceae, ordem Gentianales. É nativa de uma região localizada entre o Sudoeste da Etiópia, Sudeste do Sudão e Norte do Quênia e apresenta distribuição nas Américas Central e do Sul, na África e leste da Ásia, sendo cultivada principalmente no Brasil, onde 98\% da produção concentra-se nos estados de Minas Gerais, São Paulo, Espírito Santo, Paraná e Bahia (CARVALHO, 1946; DAMATTA; RAMALHO, 2006; FERRÃO et al., 2007).

O cafeeiro é um arbusto de crescimento contínuo, com dimorfismo de ramos (RENA; MAESTRI, 1986), que atinge entre 2 e 4 metros de altura, conforme a espécie e as condições climáticas da região; as folhas são pareadas e opostas, ovais, de cor verde escura. As flores são brancas, aromáticas, reunidas em número de 2 a 6 , formando glomérulos situados na axila das folhas e geralmente abrem-se nas primeiras horas da manhã e permanecem abertas durante todo o dia. O cafeeiro possui caule cilíndrico, lenho duro, branco amarelado e dois tipos principais de ramos: ortotrópico (do grego orthós: reto, normal) e plagiotrópicos (do grego plágios: oblíquo, transversal) (RENA; MAESTRI, 1986).

Os principais compostos químicos são os alcaloides, inclusive os purínicos ou xantinas (cafeína, paraxantina, teobromina, teofilina), ácidos orgânicos (ácido clorogênico, ácidos caféico, metilúrico, vanílico, hidroxibenzoico, ferrúlico), flavonoides (caempferol, quercetol), diterpenos (cafestol, caveol), salicilatos (salicilato de metila), EDTA, ácido benzoico, derivados nicotínicos (trigonelina), óleos essenciais (ácido cinâmico, aldeído cinâmico), vitaminas (nicotinamida, ácido ascórbico, tiamina, riboflavina, caroteno) e minerais (cálcio, fósforo, ferro) (LIMA et al., 2010). 


\section{Revinter}

O alto valor comercial desta espécie está no seu fruto, ou melhor, nas suas sementes, que têm formas elípticas, ovoides, achatadas ou arredondadas (CARVALHO; MÔNACO, 1965) e corresponde à matéria prima para uma afamada bebida, o café, que por sua vez, possui propriedades medicinais, agindo como analgésico, anti-hemorrágico, antidiarreico, antiespasmódico, antigripal, anti-inflamatório, broncodilatador, cardiotônico, depurativo, desintoxicante digestivo, diurético, estimulante, excitante, expectorante, hipoglicemiante, hipotensor, tônico e vulnerário (BALMÉ, 2004).

A ingestão diária do café é um hábito comum para muitas pessoas, o que pode causar certa dependência, visto que, a supressão da ingestão dessa bebida pode, em muitos casos, provocar cefaleia e mal-estar. O efeito reverso também é notificado, pois, em alguns casos, quando consomem o café, algumas pessoas apresentam tais sintomas. Desse modo, despontam indagações referentes à constituição química e propriedades medicinais existentes nos indivíduos da espécie Coffea arabica. Logo, uma revisão bibliográfica enfocando a temática de uso medicinal do café se justifica, pois, se trata de uma espécie altamente consumida pela população mundial e que apresenta finalidades medicinais.

Este trabalho tem como objetivo principal responder ao questionamento: com tantos componentes químicos presentes na espécie Coffea arabica, quais as indicações do uso desta espécie, quais as principais formas de uso e quais são as partes dessa planta que são utilizadas com finalidade medicinal? Para tanto, realizou-se a revisão das propriedades de Coffea arabica e uma prospecção sobre seu potencial medicinal, também buscou-se descrever as suas propriedades tóxico e farmacológicas, avaliando-se o perfil quantitativo das publicações da espécie a fim de demonstrar tais propriedades quanto à redução e/ou modulação da resposta inflamatória ou da atividade anti-oxidante.

\section{METODOLOGIA}

Para esta revisão foram utilizados apenas recursos primários como os bancos de dados SciELO (Scientific Eletronic Library Online), Science Direct e Web CAPES. Foram selecionados documentos e artigos compreendendo os aspectos envolvidos direta ou indiretamente nas propriedades de Coffea arabica, a exposição humana e animal e consequências da intoxicação, incluindo artigos originais e de revisão, escritos em Português, Inglês ou Espanhol. 


\section{Revinter}

Para pesquisa dos artigos foram feitas buscas utilizando termos isoladamente ou combinados, estando sempre presente o nome da espécie (Coffea arabica) e este combinado com os termos: propriedades terapêuticas, propriedades farmacológicas, consumo, toxicidade, uso popular, metabólitos secundários, genotoxicidade e plantas medicinais.

Trinta artigos foram selecionados, cujas temáticas foram organizadas para um encadeamento de ideias, sendo ordenados da seguinte maneira: Biologia e reprodução do cafeeiro; Coffea arabica L.: potencialidades e ação medicinal, abordando acerca dos efeitos sobre o comportamento humano e desempenho em adultos, bem como, a modulação de doenças associadas ao consumo.

\section{DESENVOLVIMENTO}

\section{Biologia e reprodução do cafeeiro}

A fase reprodutiva é marcada pela capacidade da planta em produzir flores e é resultante de mudanças que ocorrem no meristema das gemas (LARCHER, 2000). No cafeeiro, o desenvolvimento reprodutivo começa com a iniciação floral e termina com a queda dos frutos. Camargo e Camargo (2001) subdividiram o ciclo fenológico completo do cafeeiro em seis fases: 1) vegetação e gemas foliares; 2) indução e maturação das gemas florais; 3) florada; 4) granação dos frutos; 5) maturação dos frutos; 6) repouso e senescência dos ramos terciários e quaternários. Pezzopane et al. (2003) descreveram uma escala das fases fenológicas reprodutivas do cafeeiro com base em números: 0 (gema dormente); 1 (gema intumescida); 2 (abotoado); 3 (florada); 4 (pós-florada); 5 (chumbinho); 6 (expansão dos frutos); 7 (grão verde); 8 (verde-cana); 9 (cereja); 10 (passa) e 11 (seco), sendo a análise histológica o melhor método para avaliar com precisão a transição das fenofases (MOENS, 1963; BARROS et al., 1978), ainda que este seja de difícil utilização prática.

O processo de floração nas plantas compreende uma sequência de eventos morfofisiológicos que vão desde a indução floral até a antese, passando por fases intermediárias. Três eventos ocorrem durante a transição da gema vegetativa para a reprodutiva; indução, evocação e iniciação, que envolvem interações entre sinais internos e externos (KRAJEWSKI; RABE, 1995). Nesta fase, observa-se um aumento da atividade mitótica entre a zona central e o "pith-rib" (zona abaixo, caracterizada por uma camada de células aplainadas e vacuolizadas), dando origem a células pequenas (BERNIER, 1988). 


\section{Revinter}

A indução floral é definida como um evento que ativa processos que permitem que a planta esteja apta para o florescimento, por meio da transcrição e da expressão de genes, que ocorrem antes da iniciação. Bernier et al. (1981) e Krajewski e Rabe (1995) referem-se à indução como uma condição fisiológica iniciada nos tecidos, em resposta às características do ambiente, sobretudo ao fotoperíodo.

\section{Coffea arabica $\mathrm{L}$. potencialidades e uso medicinal}

Santos et al. (2007) realizaram um estudo sobre a atividade antioxidante do café. Algumas amostras foram torradas em torrador de laboratório com capacidade de $1 \mathrm{~kg}$, em graus de torrefação claro, médio e escuro. O ponto de torrefação foi determinado visualmente, em 5 repetições. Em seguida, os grãos torrados foram moídos (moedor elétrico Raiar, modelo RA21) em granulometria fina, empacotados em embalagens de polietileno/alumínio/polipropileno, seladas a vácuo e estocada a $-20^{\circ} \mathrm{C}$ até o preparo da bebida. Após o preparo da bebida foi analisada a determinação do grau de torrefação, avaliação espectrofotométrica da bebida de café, determinação do caráter aromático, perfil cromatográfico e avaliação da atividade antioxidante e do poder redutor. Foi observado que todas as bebidas de café estudadas apresentaram atividade antioxidante dependente da concentração. As amostras de café com grau de torrefação claro foram as que apresentaram maior poder redutor e atividade sequestrante de radicais DPPH, enquanto que a capacidade quelante de ferro não diferiu das amostras com grau de torrefação médio, mas foi menor que a capacidade quelante do café verde.

Apenas para o teste de poder redutor observou-se que o processamento semiúmido foi mais eficiente que o processamento seco. Todas as amostras apresentaram alta atividade de inibição da peroxidação lipídica. Assim, pôde-se concluir que o grau de torrefação parece ser mais importante que o tipo de processamento do café na determinação da atividade antioxidante da bebida (SANTOS et al., 2007). 
Em culturas ocidentais, o café consumido nas primeiras horas da manhã aparece como item indispensável para conferir uma predisposição positiva às atividades diárias. Smith et al. (1999) foram capazes de caracterizar indivíduos com base no café e em cereais consumidos na primeira refeição do dia. Indivíduos que consomem café e cereal demonstraram um clima mais positivo no início das sessões dos testes, tiveram melhor desempenho em uma memória espacial e sentiram-se mais calmos no final da sessão de teste, quando comparados àqueles condicionados à ausência do café da manhã. A ingestão de cafeína não despontou efeito sobre o humor inicial ou memória de trabalho, mas fez melhorar a codificação de novas informações e combater o cansaço que se desenvolveu através da sessão de teste (SMITH et al., 1999).

Vários trabalhos incitam o consumo de café no local de trabalho (STEPTOE; WARDLE, 1999), uma vez que, acredita-se que o mesmo conduza a um maior desempenho (JARVIS, 1993). Horne e Reyner (1995) e Reyner e Horne (2000) sugeriram que a dose de cafeína ingerida através de café reduz a sonolência de motoristas no início da manhã. Entretanto, ainda que a sonolência de motoristas tenha papel direto na ocorrência de acidentes de viação, a informação pode ser mal avaliada, caso a ingestão ocorra como meio preventivo do sono durante a condução (REY DE CASTRO et al., 2004).

O teor de cafeína de cafés varia de 58 para $259 \mathrm{mg} /$ dose. Em um estudo, a média do teor de cafeína de cafés especiais fabricados foi de $188 \mathrm{mg}$ para 6 oz (EUA) xícara (BELL et al., 1996). A variabilidade é, no entanto, alta. McCusker et al. (2003) relataram uma vasta gama de concentração de cafeína (259-564 mg/dose) na mesma bebida de café obtido a partir da mesma tomada em seis dias consecutivos.

Cerca de $80 \%$ da população mundial consome cafeína diariamente através do café, chás e refrigerantes, sendo o café a fonte mais importante, contribuindo com $71 \%$ da cafeína da dieta dos americanos. Estima-se que uma xícara de 150 mL de café contenha de 66 a 99 mg de cafeína no café infundido, 66 a $81 \mathrm{mg}$ de cafeína no instantâneo, 48 a 86mg de cafeína no fervido, de 58 a 76mg de cafeína no expresso e de 1,3 a 1,7mg de cafeína no descafeinado (BONITA et al., 2007; NAKASACO, 2001).

Mais de $99 \%$ da cafeína consumida por via oral é absorvida pelo trato gastrintestinal, atingindo a corrente sanguínea em sessenta minutos e, em seguida, exercendo suas ações fisiológicas. Sua principal ação fisiológica é como antagonista da adenosina, um potente neuromodulador endógeno, com efeito, principalmente, inibitório. Em função da semelhança estrutural, a cafeína compete pelos receptores da adenosina produzindo estímulo no Sistema Revinter, v. 11, n. 03, p. 87-105, out. 2018. 
Nervoso Central (SNC), aumento agudo da pressão arterial (PA) e aumento da velocidade metabólica e da diurese. No sistema cardiovascular, produz aumento agudo do débito cardíaco, vasoconstricção e aumento da resistência vascular periférica. Contrariamente a estes efeitos indesejáveis, alguns estudos in vitro têm demonstrado atividade antioxidante da cafeína (HIGDON; FREI, 2006; SUDANO et al., 2005; BONITA et al., 2007) o que a tornaria um protetor em potencial contra os efeitos citados no sistema cardiovascular.

Além da cafeína e dos diterpenos, o café é uma importante fonte de compostos fenólicos não flavonóides (ácidos fenólicos), especialmente de ácidos clorogênicos (formados a partir da esterificação do ácido quínico com ácidos hidrocinâmicos), dos quais o ácido caféico apresenta a maior capacidade protetora antioxidante, devido à existência de duas hidroxilas nas posições 3 e 4 na sua estrutura química (SOARES, 2002; FARAH; DONANGELO, 2006). O café como bebida apresenta uma quantidade de ácidos clorogênicos que varia dependendo do estudo, em média, de 70 a 350mg/xícara de 200 mL (HIGDON; FREI, 2006), de 200 a 550mg/xícara de $200 \mathrm{~mL}$ (NATELLA et al., 2007) e 396mg/xícara de $180 \mathrm{~mL}$ (BONITA et al., 2007).

Além da importância para a formação de aroma e sabor, os ácidos clorogênicos possuem também bioatividade (FARAH; DONANGELO, 2006). Robinson et al., (1996) demonstraram que o ácido 3,5-dicafeoilquínico é um potente inibidor da integrase do vírus da imunodeficiência em humanos (HIV-1), uma enzima requerida para infecção das células. $\mathrm{O}$ ácido 5-cafeoilquínico, o ácido caféico e toda família destes ácidos mostraram-se potentes antioxidantes em eritrócitos humanos (DE MARIA et al., 1999). Além disso, também foram observados: o efeito indutor na replicação e na mobilidade de macrófagos de camundongos, o que acarretaria um aumento da imunidade (TATEFUJI et al., 1996); características antimutagênicas (STICH et al., 1982; WATTENBERG, 1983); a indução da diminuição dos níveis sanguíneos de glicose por meio da inibição da enzima glicose-6-fosfatase (ARION et al., 1998; HERLING et al., 1998) e também, propriedades antibacterianas (DOGASAKI et al., 2002; DAGLIA et al.,1998).

Moreira et al. (2012) demonstraram que os extratos aquosos de C. arabica despontaram ação anti-inflamatória considerável, aliviando edema e dor induzida por formalina e LPS, reduzindo a indução da migração de leucócitos no teste de peritonite. O mecanismo de efeito pode ser devido à presença de substâncias anti-inflamatórias como flavonoides e antioxidantes, que estão presentes em Coffea. Os resultados sugerem um efeito anti-inflamatório melhor para 
o extrato de café verde em comparação com café torrado. No futuro, os extratos de C. arabica podem ter um valor potencial terapêutico no tratamento de distúrbios inflamatórios.

Os efeitos do café sobre o trato gastrointestinal, do fígado e sistema biliar são conhecidos e são atribuídos aos vários componentes, tais como a cafeína e ácido clorogênico ou ácidos caféicos. Os efeitos estimulantes sobre esses órgãos podem ser causados direta ou indiretamente pela liberação de gastrina ou outros hormônios gastrointestinais (CZOK, 1977).

Existe uma associação inversa entre o consumo de café e cirrose hepática (KLATSKY; ARMSTRONG, 1992; GALLUS et al., 2002; TVERDAL; SKURTVEIT, 2003). Corrao et al. (2001) discutiram a hipótese de que o café, mas não outras bebidas com cafeína, pode inibir o aparecimento de cirrose hepática não alcoólica. Beber café também foi associado com um risco reduzido de pancreatite associada ao álcool (MORTON et al. 2004).

Segundo Dórea e Da Costa (2005), estudos experimentais demonstraram efeitos positivos da ingestão normal de café em vários aspectos da saúde, tais como resposta psicoativa (estado de alerta, mudanças de humor), neurológicas (hiperatividade infantil, doença de Parkinson) e distúrbios metabólicos (diabetes, cálculos biliares) e função gonadal e do fígado. Ao contrário de outros alimentos funcionais que podem agir sobre uma população definida, com um efeito especial, a utilização do café é ampla (desde crianças a idosos), com um amplo espectro de benefícios para a saúde. Muitos estudos suportam a ideia de que beber café tem benefícios para a saúde. Assim, é simples de conceituar o café como um alimento funcional.

Morte devido à ingestão excessiva de cafeína não é comum e apenas alguns casos foram relatados na literatura. A dose letal aguda em seres humanos adultos foi estimada como sendo de $10 \mathrm{~g} /$ pessoa, ocorrendo relato após a ingestão de 6,5 g de cafeína, entretanto há registro da sobrevivência de um paciente em que a cafeína ingerida foi alegadamente $24 \mathrm{~g}$. A toxicidade da cafeína em adultos pode apresentar um espectro de sintomas clínicos, que vão de nervosismo, irritabilidade e insônia a perturbações sensoriais, diurese, arritmia, taquicardia, respiração elevada e perturbações gastrointestinais. A toxicidade da cafeína em crianças é manifestada por êmese grave, taquicardia, agitação do sistema nervoso central e diurese. A exposição crônica a cafeína tem sido implicada em uma gama de disfunções do trato gastrointestinal envolvendo o sistema do fígado, sistema renal e musculatura (STAVRIC, 1988; JAMES, 1991a).

O mecanismo mais importante de ação de cafeína é o antagonismo dos receptores de adenosina. Adenosina é uma purina libertado localmente que atua em diferentes receptores que podem aumentar ou diminuir as concentrações celulares de monofosfato cíclico de adenosina Revinter, v. 11, n. 03, p. 87-105, out. 2018. 
(acampar). Cafeína bloqueia seletivamente os receptores de adenosina e inibe competitivamente a ação da adenosina em concentrações encontradas em pessoas que consomem cafeína a partir de fontes dietéticas. Resultados da cafeína como a liberação de norepinefrina, dopamina e serotonina no cérebro e o aumento de catecolaminas circulantes, são consistentes com a reversão do efeito inibitório de adenosina (BENOWITZ, 1990).

Os resultados dos estudos sobre os efeitos da cafeína sobre várias tarefas psicomotoras são algumas vezes conflitantes. Alguns estudos demonstraram não haver efeitos da cafeína sobre a firmeza das mãos, enquanto outros associaram o consumo de cafeína a um pior desempenho neste parâmetro (BOVIM et al., 1995).

Em alguns casos não foi percebido a mudança de humor após o consumo de doses únicas de cafeína de 32 mg (LIEBERMAN et al., 1987), 100 mg (SVENSSON et al., 1980) ou 200 mg (SWIFTT; IPLADY, 1988). Maiores quantidades de cafeína (200, 400 ou 600 mg como uma única dose) têm sido associados não apenas com ligeiros aumentos em escala raiva/hostilidade, mas também com classificações reduzidas para sonolência e descoordenação (ROACHE; GRIFFITHS, 1987). A cafeína tem pouco efeito na produção de depressão, até mesmo para o consumo de mais de oito xícaras de café por dia (JAMES, 1991b). Não está claro por que alguns estudos encontraram efeitos sobre humor e outros não.

A literatura sobre o desenvolvimento de tolerância aos efeitos da cafeína durante a ingestão prolongada é esparsa e inconsistente (JAMES, 1991c). Qualquer tolerância que pode estar presente é susceptível de ser dependente do efeito biológico ou comportamental produzido pela cafeína e pelo nível e padrão de consumo de cafeína.

Cessação da ingestão de cafeína tem sido associada com uma ampla variedade de efeitos subjetivos, principalmente a dor de cabeça (RUBIN; SMITH, 1999) e fadiga, caracterizada por sintomas mentais tais como a depressão, fraqueza, letargia, apatia, sonolência e diminuição do alerta (GRIFFITHS; WOODSON, 1988). O padrão geral na retirada da cafeína parece ter um início de 12 a 24 h após a interrupção, a um pico 20-48 h, e uma duração de cerca de 1 semana (GRIFFITHS; WOODSON, 1988). A força da associação entre o encerramento e a retirada da cafeína é apoiada pelo facto de que os sintomas podem ser melhorados por administração de comprimidos de cafeína de uma forma dependente da dose. A intensidade dos sintomas tem sido descrita como suave a extremo, sendo a presença ou ausência de sintomas na retirada nem sempre previsível (GRIFFITHS; WOODSON, 1988).

Os sintomas associados à abstinência de cafeína têm sido observados em estudos Revinter, v. 11, n. 03, p. 87-105, out. 2018. 


\section{Revinter}

envolvendo a cessação desde o consumo regular, de alta $(\leq 1250 \mathrm{mg} /$ dia) (GRIFFITHS et al., 1986); $\leq 2548 \mathrm{mg} / \mathrm{dia}$ (STRAIN et al., 1994) e doses muito mais baixas (100 mg dia) (GRIFFITHS et al., 1990); $235 \mathrm{mg} /$ dia (SILVERMAN et al., 1992); $290 \mathrm{mg} / \mathrm{dia}$ (WEBER et al., 1993); $428 \mathrm{mg} / \mathrm{dia}$ (BRUCE et al., 1991); quatro a seis xícaras de café por dia (VAN DUSSELDORP; KATAN, 1990); cinco xícaras de café por dia (HUGHES et al., 1991).

Enquanto alguns estudos têm mostrado um aumento dependente da dose dos efeitos de retirada (aumento da dor de cabeça após a paralisação do consumo regular de > $700 \mathrm{mg}$ cafeína/dia em comparação com $\leq 700 \mathrm{mg}$ /dia) (WEBER et al., 1993), outros têm mostrado pouca correlação entre admissão diária e de sintomas de privação (em um intervalo de ingestão regular de 231-2548 mg/dia) (STRAIN et al., 1994). Para Strain et al. (1994), os efeitos mais graves após a cessação foram observados com o menor consumo, enquanto o indivíduo normal com o maior consumo foi relatado apenas efeitos moderados.

Muitos artigos foram publicados, inicialmente, incriminando a cafeína e culpando o café como um grande vilão para as doenças cardíacas, dentre elas o infarto do miocárdio. Entretanto, atualmente, está bem caracterizado não haver nenhuma relação entre o consumo de café e a ocorrência de doença coronariana, arritmias cardíacas, hipertensão arterial bem como óbitos em decorrência dessas doenças ou causas diversas, em homens e mulheres com 30 a 59 anos de idade (WILLETT et al., 1996; KLEEMOLA et al., 2000).

Com mais cautela, Lima (2001) sugere que apenas o consumo excessivo de café (superior a seis xícaras diárias) pode duplicar o risco de infarto do miocárdio. O fato de que o café provoca hipertensão arterial, mito tradicionalmente aceito há 60 anos, sem qualquer prova científica, também foi recentemente desvendado pela equipe do Dr. Michael Klag, da Faculdade de Medicina da Johns Hopkins University, nos Estados Unidos. Para esses cientistas, o hábito de beber café exerce uma pequena influência no aumento da pressão sanguínea, mas não parece acentuar o risco do desenvolvimento de hipertensão (KLAG et al., 2002).

Evidências científicas reunidas ao longo das duas últimas décadas indicam que a cafeína, consumida em quantidades moderadas, não só não faz mal como resulta em ganhos para a saúde humana como um todo. Por sua vez, seu consumo excessivo, como o de qualquer outro alimento, pode ser prejudicial. Lima (1989) e Flores et al. (2000) recomendam que o Revinter, v. 11, n. 03, p. 87-105, out. 2018.

Página 96 | 105 


\section{Revinter}

consumo diário de cafeína para uma pessoa adulta e saudável não deve ultrapassar 500 mg. Lima (2001) afirma ainda que, em quantidades moderadas, de 400 a $500 \mathrm{mg}$ ou de 3 a 4 xícaras, a cafeína não é prejudicial à saúde humana, desde a gestação até o final da vida.

Para Lima (2001), o café deve ser ingerido durante o período diurno, sendo a primeira xícara tomada na primeira hora após o despertar, e as demais, com intervalos mínimos de 2 horas. Após as 15 h - 16 h (última dose), o cérebro começa lentamente a diminuir sua atividade, quando o ciclo do sono inicia sua função, levando o indivíduo a dormir por volta das 22 horas. Assim, o café atua de maneira perfeitamente integrada com o cérebro humano e o ciclo sono vigília. A dose máxima diária para uma pessoa adulta e saudável é de 0,5 L de café, ou seja, 5 xícaras de $100 \mathrm{~mL}$, distribuídas ao longo do dia. Caso uma pessoa tome, de uma só vez, meio litro de café, pode apresentar uma série de problemas. Obviamente, algumas pessoas são mais sensíveis que outras e uma xícara de café de $100 \mathrm{~mL}$ também pode causar excitação, nervosismo, inquietude e mal-estar. Por isso, o consumo deve ser sempre iniciado com uma xícara pequena de $50 \mathrm{~mL}$ e, gradativamente, ser aumentado até um consumo normal, dependendo da idade do indivíduo.

No início da década de 80, cientistas australianos mostraram que o pó de café - torrado e moído - tem propriedades semelhantes ao naloxone, quanto a sua ligação a receptores opioides em cérebros de ratos (BOUBLIK et al., 1983). E não havia diferença entre o café normal e o descafeinado. Os cientistas mostraram ainda, que o café possui outros componentes, além da cafeína, que atuam em receptores opioides da mesma forma que o naloxone - com ação antagonista opioide. Eles concluíram que 1 xícara de café possui uma quantidade dessa substância equivalente à dose de 1/3 de uma ampola de naloxone, despertando pela primeira vez, a hipótese de que tomar café pode implicar num envolvimento do sistema opioide do sistema nervoso central.

Estudos epidemiológicos detectaram uma associação benéfica de uma moderada ingestão diária de café com menor incidência de cirrose e de suicídio entre adultos (KLATSKY et al., 1993) e uma alta relação inversa entre ingestão de café e risco de suicídios em mulheres de 34 a 59 anos de idade (KAWACHI et al., 1996). Entretanto, os efeitos do café não foram atribuídos a possíveis efeitos de elevação do humor ou efeitos antidepressivos da cafeína. Corrao et al. (2001) mostraram que o consumo de café - e não de outras bebidas cafeinadas pode inibir o início da cirrose hepática causada tanto por álcool quanto por vírus. 


\section{Revinter}

Estudos clínicos têm investigado os efeitos da cafeína ou café em arritmia cardíaca, frequência cardíaca, o colesterol no soro e a pressão arterial. Estudos epidemiológicos têm amplamente focado sobre a associação entre o consumo de café e os fatores de risco cardiovascular, incluindo a pressão sanguínea e os níveis de colesterol no soro, ou a incidência de doença cardiovascular (NAWROT et al., 2002).

Os estudos têm demonstrado que doses únicas de cafeína <450 mg não aumentam a frequência ou severidade de arritmias cardíacas em pessoas saudáveis, pacientes com doença cardíaca isquêmica ou naqueles com ectopia ventricular grave (MYERS, 1998). Estudos realizado em indivíduos saudáveis ou hipertensos sugerem que, quando uma alteração na frequência cardíaca é observada, é tipicamente um decréscimo em doses $>150 \mathrm{mg} /$ pessoa (JAMES, 1991c; GREEN et al., 1996; MYERS, 1998). O rápido desenvolvimento de tolerância ao efeito da taxa de cafeína no coração (GREEN et al., 1996) complica a interpretação dos dados. É provável haver uma redução modesta na frequência cardíaca, porém, clinicamente irrelevante (MYERS, 1998).

Vários outros estudos clínicos e epidemiológicos têm sugerido que o consumo de café está associado com aumentos significativos nos níveis de colesterol total e lipoproteína de baixa densidade. Outras pesquisas, contudo, sugerem que a cafeína presente no café não é responsável pelos efeitos hipercolesterolêmicos (THELLE et al., 1987; JAMES, 1991c; THELLE, 1993, 1995; GARDNER et al., 1998). Dois diterpenóides, álcoois cafestol e kahweol, encontrados em níveis significativos em café fervido foram identificados como componentes hipercolesterolêmicos. Embora estes componentes sejam em grande parte, separados pela utilização de um filtro de papel na preparação de café, há alguma evidência de que o consumo de café filtrado está associado com pequenos aumentos nos níveis de colesterol sérico (THELLE, 1995). 


\section{Revinter}

\section{CONSIDERAÇÕES FINAIS}

Foi possível observar diante deste trabalho que a espécie Coffea arabica tem bastante fins medicinais como: atividade antioxidante, efeitos anti-inflamatório, redução na taxa do fotoenvelhecimento e uso para fins de doenças crônicas. Também apresenta muitas potencialidades como um tipo de alimento funcional por apresentar efeitos estimulantes, mudanças no humor, bem como atividades motoras e cerebrais

Levando em consideração o seu uso moderado, a espécie em questão apresenta benefícios para o ser humano. Substâncias como ácidos clorogênicos e a cafeína podem ser ingeridas através da bebida ou extraídas e usadas para fins medicinais. O consumo diário e moderado de café pode trazer benefícios para algumas pessoas e pode ser prejudicial para outras, sendo necessário mais estudos que aprofundem e monitores o seu consumo na população.

\section{REFERÊNCIAS BIBLIOGRÁFICAS}

ARION, W. J.; CANFIELD, W. K.; RAMOS, F. C.; SU, M. L.; BURGER, H. J.; HEMMERLE, H.; SCHUBERT, G.; BELOW, P.; HERLING, A. W. 1998. Chlorogenic acid analogue S 3483: a potent competitive inhibitor of the hepatic and renal glucose-6-phosphatase systems. Archives of Biochemistry and Biophysic, 351(2):279-85.

BALMÉ, F. 2004. Plantas Medicinais, $1^{\text {a }}$ ed. São Paulo: Hemus.

BARROS, R. S.; MAESTRI, M.; COONS, M.P. 1978. The physiology of flowering in coffee: a review. Journal of Coffee Research, 8(2-3):29-73.

BELL, L.N.; WETZEL, C.R.; GRAND, A.N. 1996. Caffeine content in coffee as influenced by grinding and brewing techniques. Food Research International, 29(8):785-789.

BENOWITZ, N. L. 1990. Clinical pharmacology of caffeine. Annual Review of Medicine, 41:277-288.

BERNIER, G.; KINET, J. M.; SACHS, R. M. 1981. The physiology of flowering. Boca Raton: CRC, 149p. 
BERNIER, G. 1988. The control of floral evocation and morphogenesis. Annual Review of Plant Physiology Plant Molecular Biology, 39:175-219.

BONITA, J. F.; MANDARANO, M.; SHUTA, D.; VINSON, J. 2007. Coffee and cardiovascular disease: in vitro, cellular, animal, and human studies. Pharmacological Research, 55(3): 187-98.

BOUBLIK, J. H.; QUINN, M. J.; CLEMENTS, J. A.; HERINGTON, A. C.; WYNNE, K. N.; FUNDER, J. W. 1983. Coffee contains potent opiate receptor binding activity. Nature, 301: 246-248.

BOVIM, G.; NAESS, P.; HELLE, J.; SAND, T. 1995. Caffeine influence on the motor steadiness battery in neuropsychological tests. Journal of Clinical and Experimental Neuropsychology, 17(3):472-476.

BRUCE, M.; SCOTT, N.; SHINE, P.; LADER, M. 1991. Caffeine withdrawal: a contrast of withdrawal symptoms in normal subjects who have abstained from caffeine for 24 hours and for 7 days. Journal of Psychopharmacology, 5(2):129-134.

CAMARGO, A. P.; CAMARGO, M. B. P. 2011. Definição e esquematização das fases fenológicas do cafeeiro arábica nas condições tropicais do Brasil. Bragantia, 20(1):65-68.

CARVALHO, A.; MONACO, L.C. 1965. Natural cross pollination in Coffea arabica. In: INTERNATIONAL HORTICULTURAL CONGRESS, 26, Brussels. Proceedings. Toronto: International Horticultural Society, 4:447-449.

CARVALHO, A. 1946. Distribuição geográfica e classificação botânica do gênero Coffea com referência especial à espécie Arabica. Separata dos Boletins da Superintendência dos Serviços do Café, São Paulo, p.226-230, 1946.

CORRAO, G.; ZAMBON, A.; BAGNARDI, V.; D’AMICIS, A.; KLATSKY, A. 2001. Coffee, caffeine, and the risk of liver cirrhosis. Annals of Epidemiology, 11(7):458-465.

CZOK, G. 1977. Coffee and health. Zeitschrift Fur Ernahrungswissenschaft, 16(4): 248255.

DAGLIA, M.; PAPETTI, A.; DACARRO, C.; GAZZANI, G. 1998. Isolation of an antibacterial componente from roasted coffe. Journal of Pharmaceutical and Biomedical Analysis, 18(11):219-225.

DAMATTA, F. M.; RAMALHO, J. D. C. 2006. Impacts of drought and temperature stress on coffee physiology and production: a review. Brazilian Journal of Plant Physiology, 18(1):5581 .

DE MARIA C. A.; MOREIRA, R. F. A; TRUGO, L. C. 1999. Componentes voláteis do café torrado. Parte I: compostos heterocíclicos. Química Nova, 22(2):209. 


\section{Revinter}

DOGASAKI, C.; SHINDO, T.; FURUHATA, K.; FUKUYAMA, M. 2002. Identification of chemical antibacterial components against Legionela pneumophilia in a coffe beverage J. The Pharmaceutical Society of Japan, 122(7):487-494.

DÓREA, J. G.; DA COSTA, T. H. M. 2004. Is coffee a functional food?. British Journal of Nutrition, 93(6):773-82.

FARAH, A.; DONANGELO, C.M. 2006. Phenolic compounds in coffee. Brazilian Journal Plant of Physiololy, 18(1):23-26.

FERRÃO, M. A. G.; FONSECA, A. F. A. da.; VERDIN FILHO, A. C.; VOLPI, P. S. 2007. Origem, dispersão geográfica, taxonomia e diversidade genética de Coffea canephora. In: FERRÃO, R. G.; FONSECA, A. F. A. da.; BRAGANÇA, S. M.; FERRÃO, M. A. G.; DE MUNER, L. H. (Ed.). Café Conilon. Vitória: Incaper, p. 264-91.

FLORES, G. B.; ANDRADE, F.; LIMA, D. R. 2000. Can coffee help fighting the drug problem? Preliminary results of a Brazilian youth drug study. Acta Pharmacologica Sinica, 21(12):059-1070.

GALLUS, S.; TAVANI, A.; NEGRI E, L.A.; VECCHIA, C. 2002. Does coffee protect against liver cirrhosis? Annals of Epidemiology, 12(3):202-205.

GARDNER, C.; BRUCE, B.; SPILLER, G. 1998. A. Coffee, caffeine and serum cholesterol. Caffeine, Boca Raton: CRC Press, p. 301-323.

GREEN, P. J.; KIRBY, R.; SULS, J. 1996. The effects of caffeine on blood pressure and heart rate: a review. Annals of Behavioral Medicine, 18(3):201-216.

GRIFFITHS, R. R.; BIGELOW, G. E.; LIEBSON, I. A. 1986. Human coffee drinking: reinforcing and physical dependence producing effects of caffeine. Journal of Pharmacology and Experimental Therapeutics, 239(2):416-425.

GRIFFITHS, R. R.; WOODSON, P. P. 1988. Caffeine physical dependence: a review of human and laboratory animal studies. Psychopharmacology, 94(4): 437-451.

GRIFFITHS, R. R.; EVANS, S. M.; HEISHMAN, S. J.; PRESTON, K. L.; SANNERUD, C. A.; WOLF, S.; WOODSON, P. P. 1990. Low-dose caffeine physical dependence in humans. Journal of Pharmacology and Experimental Therapeutics, 255(3): 1123-1132.

HERLING, A. W.; BURGER, H. J.; SCHWAB, D.; HEMMERLE, H.; BELOW, P.; SCHUBERT, G. 1998. Pharmacodynamic profile of a novel inhibitor of the hepatic glucose-6phosphatase system. American Journal of Physiology, 274(6):1087-93.

HIGDON, J. V.; FREI, B. 2006. Coffee and health: a review of recent human research. Critical Reviews in Food Science and Nutrition, 46(2):101-23.

HORNE, J.A.; REYNER, L.A. 1995. Driver sleepiness. Journal of Sleep Research, 4(2):2329.

Revinter, v. 11, n. 03, p. 87-105, out. 2018.

Página 101 | 105 
HUGHES, J. R. HIGGINS, S. T.; BICKEL, W. K.; HUNT, W. K.; FENWICK, J. W.; GULLIVER, S. B.; MIREAULT, G. C. 1991. Caffeine self-administration, withdrawal, and adverse effects among coffee drinkers. Archives of General Psychiatry, 48(7):611-617.

JAMES, J. E. 1991a. Toxicity. Caffeine and Health, London: Academic Press, p.63-95.

JAMES, J. E. 1991b. Psychopathology. Caffeine and Health, London: Academic Press, p.280-300.

JAMES, J. E. 1991c. Cardiovascular system. Caffeine and Health, London: Academic Press, p.96-138.

JARVIS, M. J. 1993. Does caffeine intake enhance absolute levels of cognitive performance? Psychopharmacology, 110(1-1):45-52.

KAWACHI, I.; WILLETT, W. C.; COLDITZ, G. A.; STAMPFER, M. J.; SPEITZER, F. E. 1996. A prospective study of coffee drinking and suicide in women. Archives of Internal Medicine, Chicago, 156(5):521-525.

KLAG, M. J.; WANG, N. Y.; MEONI, L. A.; BRANCATI, F. L.; COOPER, L. A.; LIANG, K. Y.; YOUNG, J. H.; FORD, D. E. 2002. Coffee intake and risk of hypertension: the Johns Hopkins precursors study. Archives of Internal Medicine, 162(6):657-662.

KLATSKY, A. L.; ARMSTRONG, M. A. 1992. Alcohol, smoking, coffee, and cirrhosis. American Journal of Epidemiology, 136(10):1248-1257.

KLATSKY, A. L.; ARMSTRONG, M. A.; FRIEDMAN, G. D. 1993. Coffee, tea and mortality. Annals of Epidemiology, 3(4): 375-381.

KLEEMOLA, P.; JOUSILAHTI, P.; PIETINEN, P.; VARTIAINEN, E.; TUOMILEHTO, J. 2000. Coffee consumtion and risk of coronary heart disease and death. Archives of Internal Medicine, 160(22):3393-400.

KRAJEWSKI, A. J.; RABE, E. 1995. Citrus flowering:A critical evaluation. Journal of Horticultural Science, 70(3):357-374.

LARCHER, W. 2000. Ecofisiologia vegetal. RiMa.

LIEBERMAN, H. R.; WURTMAN, R. J.; EMDE, G. G.; ROBERTS, C.; COVIELLA, I. L. 1987. The effects of low doses of caffeine on human performance and mood. Psychopharmacology, 92(3):308-312.

LIMA, F. A.; SANTANA, A. E. G.; ATAÍDE, T. R.; OMENA, C. M. B.; MENEZES, M, E. S.; VASCONCELOS, S. M. L. 2010. Café e saúde humana: um enfoque nas substâncias presentes na bebida relacionadas às doenças cardiovasculares. Revista de Nutrição, 23(6):1063-1073. 


\section{Revinter}

LIMA, D. R. 1089. Cafeína e Saúde. Rio de Janeiro: Record, p.130.

LIMA, D. R. 2001. Cuidado! O popular café e a poderosa mulher... podem fazer bem à saúde. Medikka Ed. Científica, p.111.

MCCUSKER, R. R.; GOLDBERGER, B. A.; CONE, E. J. 2003. Caffeine content of specialty coffees. Journal of Analytical Toxicology, 27(7):520-522.

MOENS, P. 1963. Les bougeons végétatifs et génératifs de Coffea canephora Pierre. La Cellule, Louvain, 63(2):165-244.

MOREIRA, M. E. C.; PEREIRA, R. G. F. A.; DIAS, D. F.; GONTIJO, V. S.; VILELA, F. C.; MORAES, G. O. I.; PAIVA, A. G.; SANTOS, M. H. 2012. Anti-inflammatory effect of aqueous extracts of roasted and green Coffea arabica L. Journal of functional foods, 5(1):466474.

MORTON, C.; KLATSKY, A. L.; UDALTSOVA, N. 2004. Smoking, coffee, and pancreatitis. The American Journal of Gastroenterology, 99(4):731-738.

MYERS, M. G. 1998. Cardiovascular effects of caffeine. International Life Sciences Institute Caffeine Technical Committee Working Paper.

NAKASATO, M.; GIORGI, D. M. A.; ISOSAKI, M. 2001. Mitos e verdades sobre o café e doenças do coração. Revista da Sociedade de Cardiologia do Estado de São Paulo, 11(6):1320.

NATELLA, F.; NARDINI, M.; BELELLI, F.; SCACCINI, C. 2007. Coffee drinking induces incorporation of phenolic acids into LDL and increases the resistance of LDL to ex vivo oxidation in humans. The American Journal of Clinical Nutrition, 86(3):604-9.

NAWROT, P.; JORDAN, S.; EASTWOOD, J.; ROTSTEIN, J.; HUGENHOLTZ, A.; FEELEY, M. 2003. Effects of caffeine on human health. Food Additives \& Contaminants, 20(1):1-30.

PEZZOPANE, J. R. M.; PEDRO JÚNIOR, M. J.; THOMAZIELLO, R. A.; CAMARGO, M. B. P. 2003. Escala para avaliação de estádios fenológicos do cafeeiro arábica. Bragantia, 62(3):499-505.

REY DE CASTRO, J.; GALLO, J.; LOUREIRO, H. 2004. Tiredness and sleepiness in bus drivers and road accidents in Peru: a quantitative study. Revista Panamericana de Salud Pública, v. 16(1):11-18.

REYNER, L.A.; HORNE, J. A. 2000. Early morning driver sleepiness: effectiveness of $200 \mathrm{mg}$ caffeine. Psychophysiology, 37(2): 251-256.

RENA, A. B.; MAESTRI, M. 1986. Fisiologia do cafeeiro. Associação Brasileira para Pesquisa da Potassa e do Fosfato, p.13-85. 
ROACHE, J. D.; GRIFFITHS, R. R. 1987. Interactions of diazepam and caffeine: behavioral and subjective dose effects in humans. Pharmacology, Biochemistry and Behaviour, 26(4):801-812.

ROBINSON J. R.; CORDEIRO, M.; ABDEL-MALEK, S.; JIA, Q.; CHOW, S. A.; REINECKE, M. G.; MITCHELL, W. M. 1996. Dicaffeoylquinic acid inhibitors of human immunodeficiency virus integrase: inhibition of the core catalytic domain of human immunodeficiency virus integrasse. Molecular Pharmacology. 50(4):846-55.

RUBIN, G. J.; SMITH, A. P. 1999. Caffeine withdrawal and headaches. Nutrition and Neuroscience, 2(2):123-126.

SANTOS, M.H.; BATISTA, B.L.; DUARTE, S.M.S.; LEMOS, B. 2007. Influence of processing and roasting on the antioxidant activity of cofee (Coffea arabica). Química Nova, 30(3):604-610.

SILVERMAN, K.; EVANS, S. M.; STRAIN, E. C.; GRIFFITHS, R. R. 1992. Withdrawal syndrome after the double-blind cessation of caffeine consumption. New England Journal of Medicine, 327(16):1109-14.

SMITH, A. P.; CLARK, R.; GALLAGHER, J. 1999. Breakfast cereal and caffeinated coffee: effects on working memory, attention, mood, and cardiovascular function. Physiology \& Behavior, 67(1):9-17.

SOARES, S .E. 2002. Ácidos fenólicos como antioxidantes. Revista de Nutriçã, 15(1):7181.

STAVRIC, B. KLASSEN, R.; WATKINSON, B. KARPINSKI, K.; STAPLEY, R.; FRIED, P. 1988. Variability in caffeine consumption from coffee and tea: possible significance for epidemiological studies. Food and Chemical Toxicology, 26(2):111-8.

STEPTOE, A.; WARDLE, J. 1999. Mood and drinking: a naturalistic diary study of alcohol, coffee and tea. Psychopharmacology, 141(3):315-21.

STICH, H. F.; ROSIN, M. P.; BRYSON, L. 1982. Inhibition of mutagenicity of a model nitrosation reaction by naturally occurring phenolics, coffee and tea. Mutation Research, 95(2-3):119-28.

STRAIN, E. C.; MUMFORD, G. K.; SILVERMAN, K.; GRIFFITHS, R. R. 1994. Caffeine dependence syndrome. Evidence from case histories and experimental evaluations. Journal of the American Medical Association, 272(13):1043-8.

SUDANO, I.; BINGGELI, C.; SPIEKER, L.; LÜSCHER, T. F.; RUSCHITZKA, F.; NOLL, G.; CORTI, R.. 2005. Cardiovascular effects of coffee: is it a risk factor? Progress in Cardiovascular Nursing, 20(2):65-9.

SVENSSON, E.; PERSSON, L. O.; SJOBERG, L. 1980. Mood effects of diazepam and caffeine. Psychopharmacology, 67(1):73-80.

Revinter, v. 11, n. 03, p. 87-105, out. 2018. 
SWIFT, C. G.; TIPLADY, B. 1988. The effects of age on the response to caffeine. Psychopharmacology, 94(1):29-31.

TATEFUJI, T. IZUMI, N.; OHTA, T.; ARAI, S.; IKEDA, M.; KURIMOTO, M. 1996. Isolation and identification of compounds from Brazilian propolis which enhance macrophage spreading and mobility. Biological and Pharmaceutical Bulletin, 19(7):966-70.

THELLE, D. S. 1993. Metabolic effects of coffee and caffeine intake on the cardiovascular system. Caffeine, Coffee and Health, New York: Raven, p. 151-155.

THELLE, D. S. 1995. Coffee, tea and coronary heart disease. Current Opinion in Lipidology, 6(1):25-7.

THELLE, D. S.; HEYDEN, S.; FODOR, J. G. 1987. Coffee and cholesterol in epidemiological and experimental studies. Atherosclerosis, 67(2-3):97-103.

TVERDAL, A.; SKURTVEIT, S. 2003. Coffee intake and mortality from liver cirrhosis. Annals of Epidemiology, 13(6):419-23.

VAN DUSSELDORP, M.; KATAN, M. 1990. Headache caused by caffeine withdrawal among moderate coffee drinkers switched from ordinary to decaffeinated coffee: a 12 week doubleblind trial. British Medical Journal, 300(6739): 1558-1559.

WATTENBERG, L. W. 1983. Inhibition of neoplasia by minor dietary constituents. Cancer Research, 43(5 Suppl):2448s-2453s.

WEBER, J. G.; ERETH, M. H.; DANIELSON, D. R. 1993. Perioperative ingestion of caffeine and postoperative headache. Mayo Clinic Proceedings, 68(9):928-9.

WILLETT, W. C.; STAMPFER, M. J.; MANSON, J. E.; COLDITZ, G. A.; ROSNER, B. A.; SPEIZER, F. E.; HENNEKENS, C. H. 1996. Coffee consumption and coronary heart disease in women: a ten-year follow-up. JAMA, 275(6):458-462.

\footnotetext{
' Graduação em Licenciatura em Ciências Biológicas pela Universidade Federal do Piauí.

ii Graduação em Ciências Biológicas pela Universidade Federal de Piauí; Especialização em Ecologia pela Universidade Federal do Piauí; Mestrando em Botânica pela Universidade Estadual de Feira de Santana.

iii Graduação em Ciências Biológicas pela Universidade Federal do Piauí; Especialista em Ecologia pela Universidade Federal do Piauí.

iv Graduação em Ciências Biológicas pela Universidade Federal do Piauí; Mestrado e Doutorado em Botânica pela Universidade Federal Rural de Pernambuco. E-mail para contato: mariacarolinabreu@hotmail.com
} 